\title{
Investigation begins after fatal Virgin Galactic crash
}

\section{Second commercial accident in days is a setback for private spaceflight.}

\section{Alexandra Witze}

31 October 2014 | Updated: 02 November 2014

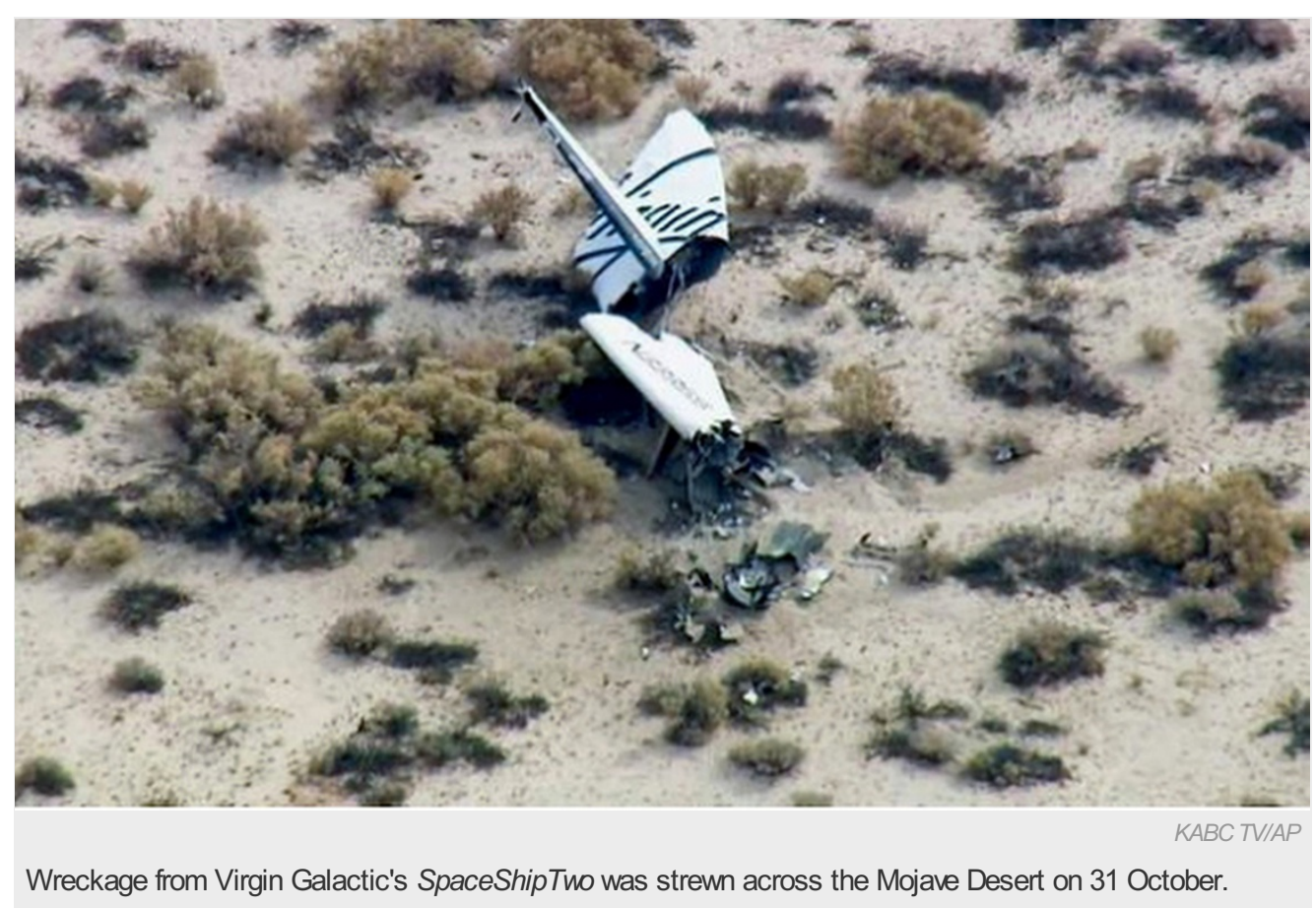

US government investigators have begun their inquiry into the 31 October crash of Virgin Galactic rocketplane SpaceShipTwo, which killed one of the craft's two pilots. Representatives of the US National Transportation Safety Board (NTSB) arrived at California's Mojave Air and Space Port on 1 November to begin surveying the wreckage.

Debris from the crash is scattered over about 8 kilometres of desert, said Christopher Hart, acting chairman of the NTSB, at a press conference. The fact that the wreckage was dispersed over such a wide area confirms that SpaceShipTwo broke up in flight rather than crashing intact, Hart said.

The debris includes the two tail booms, found farthest to the northeast, followed by the fuselage including the fuel and oxidizer tanks, Hart said. Next along the trajectory was the cockpit, and finally to the southwest was the engine.

Co-pilot Michael Alsbury, 39, was killed in the crash. He had also been co-pilot in April 2013, when SpaceShipTwo broke the sound barrier during a test flight. Pilot Peter Siebold, 43, is in hospital and recovering from his injuries; he was described as "alert and talking with his family and doctors" in a 1 November press release from Scaled Composites, the company that designed and built SpaceShipTwo for the space-tourism company Virgin Galactic. Siebold is director of flight operations at Scaled Composites, which is based in Mojave.

It is not clear how Siebold managed to get out of the plane. Hart said that a parachute was found near him. Alsbury's body was found in the wreckage.

\section{Thorough investigation}

Investigators expect to remain in Mojave for up to a week, and the full report on what went wrong may take up to a year to produce, Hart said. But the NTSB is likely to issue preliminary recommendations based on its findings. The investigation team has broken into units to examine aspects of the crash including the vehicle, the engine, data and operations.

SpaceShipTwo was on a test flight, meant to experiment with a new rocket motor and fuel blend, so it was carrying six cameras to document the flight, Hart said. The plane that took it to launch altitude, WhiteKnightTwo, carried three cameras, and there were further 
cameras on a chase plane that followed the spaceship. The crash "was heavily documented in ways that we don't normally see”, said Hart.

The investigation is the NTSB's first into a commercial space accident. The agency is normally charged with studying aeroplane crashes.

Business tycoon Richard Branson, founder of Virgin Galactic, was sombre during a brief appearance to the press on the morning of 1 November. "We've always known that commercial space travel is an incredibly hard project," he said. "We do understand the risks involved, and we're not going to push on blindly." He added that anyone who had already signed up for a Virgin Galactic flight and wanted a refund would get one.

"Space is hard, and today was a tough day," said George Whitesides, chief executive of Virgin Galactic, at a press conference at the Mojave Air and Space Port on the day of the crash.

\section{Serious setbacks}

The accident followed the 28 October explosion of an uncrewed Antares rocket that was being launched from Wallops Island, Virginia, by Orbital Sciences of Dulles, Virginia. No one was hurt in that incident, in which the craft was carrying cargo to the International Space Station.

"It's not been a good week," astronaut Leroy Chiao told US news channel CNN.

SpaceShipTwo was on its fourth rocket-powered flight, its first since January. The company had announced in May that it was switching from a rubber-based fuel to a plastic-based one to boost performance.

"We were flying a rocket motor today that had been thoroughly tested on the ground," said Kevin Mickey, president of Scaled Composites. He called the change in fuel type a "small nuance" but confirmed that the test flight was the first involving the new fuel.

\section{Commercial craft}

The US\$500-million SpaceShipTwo is intended to carry 6 paying passengers to an altitude of 100 kilometres, the edge of space, for approximately 5 minutes of weightlessness. Branson has said that he would be on the first commercial flight as early as next year, although he has repeatedly pushed that date back.

In 2004, an earlier version of the plane, SpaceShipOne, became the first private craft to reach the edge of space; in doing so, it won the \$10-million Ansari XPrize. Like its predecessor, SpaceShipTwo is carried to launch altitude by a jet-powered aeroplane, then detaches itself and fires its rocket engines to gain height. After soaring to suborbital space, it glides back to Earth and lands like a plane.

The future of Virgin Galactic's endeavour was in serious doubt hours after the crash, as television feeds relayed images of debris, including a spaceship tail emblazoned with the Virgin logo.

Something apparently went wrong shortly after the craft separated from WhiteKnightTwo, although details were scarce in the immediate aftermath. Stuart Witt, chief executive of Mojave Air and Space Port, who was at the launch, said that he did not hear or see anything abnormal at first. "It was what I was not hearing and not seeing," he said. Emergency responders found portions of the spaceship as far as 41 kilometres north of the spaceport.

This is not the first fatal accident that Scaled Composites has had on the SpaceShipTwo project. In 2007, three workers were killed on the ground in an explosion during a rocket-engine test.

A second SpaceShipTwo has been under construction. Advance tickets for tourist flights have sold for as much as $\$ 250,000$.

Nature | doi:10.1038/nature.2014.16265

\section{Updates}

Updated:This story was updated on 2 November. The original version was published on 31 October under the headline 'Crash of 
Virgin Galactic vehicle kills one'. 